\title{
Construction and Application of Practical Teaching Platform of "Subject Integration" for Engineering Management Major
}

\author{
Zhangsheng Liu*, Wenjin Xie, Wenhai Zeng, Zhenggen Fan \\ College of City Construction, Jiangxi Normal University, Nanchang, China \\ Email: ${ }^{*}$ liuzs8033@hust.edu.cn
}

How to cite this paper: Liu, Z.S., Xie, W.J., Zeng, W.H. and Fan, Z.G. (2018) Construction and Application of Practical Teaching Platform of "Subject Integration" for Engineering Management Major. Open Journal of Social Sciences, 6, 183-188.

https://doi.org/10.4236/jss.2018.612016

Received: December 10, 2018

Accepted: December 25, 2018

Published: December 28, 2018

Copyright $\odot 2018$ by authors and Scientific Research Publishing Inc. This work is licensed under the Creative Commons Attribution International License (CC BY 4.0).

http://creativecommons.org/licenses/by/4.0/

\begin{abstract}
In order to solve the problem that education mode and teaching method do not match with the rapid development of the times, this paper discusses the construction and application of the practical teaching platform of "subject integration" according to the characteristics of the complexity and applicability of engineering management specialty. Building "subject integration" practical teaching platform is a basic teaching system combining basic resources of the university teaching, simulated practical teaching and the university-company practical teaching. In order to achieve the "primary, intermediate and ultimate" three-stage target during the educational process, discipline system and professional teachers are necessarily required as the strong support in achieving the "integration of course teaching" and "integration of specialty and social competence" through the teaching of simulating scene and project case teaching.
\end{abstract}

\section{Keywords}

Project Management, Practical Teaching Platform, Integration of Disciplines

\section{Introduction}

Engineering management is an interdisciplinary subject of engineering technology and economic management as well as an application-oriented subject, which has a high requirement for cultivating students' practical ability. However, previous studies have shown that engineering management major graduates lack perceptual understanding of the actual process of engineering, and basic and overall understanding of the management problems to be solved in engineering, and their practical ability and innovation ability are widely questioned by em- 
ployers (Dai Xiaoyan, 2011 [1]; Fu fang and Zhang Tao, 2017 [2]). Although there exists a huge shortage of qualified engineering management talents in China, engineering management specialty's the matching degree and quality of employment is necessary to be improved. The underlying reasons are the mismatches between higher education's education mode along with methods and the rapid development of the times, knowledge fragmentation problems existed among various courses, practical teaching system needed to be improved, which urgent reform is strongly needed. Therefore, it is of great practical significance to explore and establish a more complete practical teaching system for engineering management specialty to meet the requirements of society and improve the specialty's professional level.

\section{Basic Teaching System of the Platform}

In order to cultivate inter-disciplinary talents that conforming to social needs, the engineering management "subject integration" practical teaching platform aims at improving students' practical and innovation ability. In order to achieve this goal, it is necessary to construct three basic teaching systems: basic teaching resources system, simulated practical teaching system and university-company practical teaching system.

The basic resources of university teaching system mainly rely on in-class teaching, library resources and on-campus practice. Among them, classroom teaching is mainly completed through theoretical knowledge teaching by professional teachers. Library resources include electronic materials, books and other relevant materials. On-campus practice mainly consists of the experiment and practical training that are stipulated in the curriculum. Basic resources of the university teaching mainly focuses on the dissemination of basic theoretical knowledge so as to lay a solid professional foundation for the improvement of students' scientific research and practical ability.

Simulated practical teaching system is a teaching resource based on mixed reality technology. Mixed reality (MR) is the computer's virtual reality technology that makes the real world and virtual objects display and interact in the same visual space (Milgram, 1994 [3]). After more than 20 years of development, relevant technologies have shown a strong driving force for development (Huang et al., 2016 [4]). Due to its features of virtual-reality integration, real-time interaction and three-dimensional registration (Azuma, 2001 [5]), it is being comprehensively popularized in the teaching of applied disciplines abroad (Mohr, et al., 2015 [6]; Chen et al., 2016 [7]). The simulated practical teaching system enables students to increase self-participation in the virtual space through self-play, so as to give full play to the initiative of students.

The university-company practical teaching system focuses on students' cognition and practice of basic knowledge and professional theories. By integrating social resources and campus resources, the school designs practical training teaching that is conducive to the improvement of students' practical and innovative ability. The research and development center of industry-university-research 
cooperation are jointly built through school-enterprise cooperation to achieve the integration of industry and education, and cultivate a new model of school-enterprise co-management and co-education.

\section{Three-Stage Target of Platform Operation}

In different stages, the practice teaching platform also has different goals. Specifically speaking, it consists of three stages: the initial stage, the intermediate stage and the final stage. Each stage has different goals and tasks step by step.

The primary stage is dominated by general education designed for lower grade stage, which contains two-layer goals, namely, to cultivate students' professional thinking ability and basic cognition of the specialty. At this stage, theoretical knowledge is to be given priority and practical teaching is complementary. Through military training, various community competitions, computer basic training, professional cognitive practice and a variety of professional software learning, to achieve the phased goals.

The intermediate stage is the key period of in-school education with the goal of cultivating professional knowledge and practical ability. The teaching content of this stage mainly includes strengthening the understanding of professional knowledge and improving the level of professional practice. The mastery of professional knowledge depends on teachers' in-depth explanation and students' literature searching, which is mainly played by basic resources of the university teaching system. At this stage, the cultivation of practical ability relies on the simulation reality teaching based on VR simulation teaching and relevant simulation project laboratory in the simulation reality teaching. Through VR virtual technology, students apply their professional knowledge to virtual construction projects. Students' primary practical ability is cultivated with the help of some virtual construction process monitoring and simulation project laboratory.

The ultimate stage of "subject integration" of engineering management should be realized in the senior grades, which is shown as the high degree of integration of professional knowledge and practical ability. Through the training in the primary and intermediate stages, students have basically mastered relevant professional knowledge and preliminarily acquired practical ability. However, practical ability is still lacking. This stage, social resources and campus resources are able to be fully used mainly through school-enterprise cooperation, so that students have the opportunity to obtain a longer period of social practice, and accumulate practical experience. With the long-time accumulation of practical experience, students' basic quality of engineering management can be cultivated, so can application-oriented talents required by employers.

\section{4. "Two Elements" of Platform Construction}

In order to realize the training goal of "subject integration" of engineering management, the two important factors for the construction of practical teaching platform include discipline system and professional teacher's ability. 
The traditional discipline system emphasizes the imparting of specialized theory and the examination of graduation thesis, which largely ignores the examination of practical ability in each stage. In the primary stage, practical class hours account for less, resulting in students' lack of understanding of professional knowledge and cognition of engineering practice. In the intermediate stage, the domestic practical teaching of engineering management specialty is mainly sand table simulation and simulation training. Zhang, et al. (2011) [8] view that sand table stimulation for engineering project management, used for breaking the weak status quo of practical teaching, subjects to the data feasibility and the fatal flaws in project information update. Li and Miao (2012) [9], Fu and Zhang (2017) successively study the simulation laboratory combining the virtuality and reality, and find that this mode fully excite students' initiative and enthusiasm in experiments, thus improving the effect of practical teaching. However, although the simulation and practical training have to a certain extent achieved the "combination of the virtuality and reality", real-time interaction is still not possible as limited by the traditional unidirectional simulation mode, which makes it difficult for students to improve their divergent thinking and innovation ability. However, in the ultimate stage, the problem of subject integration still needs to be further strengthened although graduate internship and dissertation to some extent can alleviate the problem of knowledge separation among various disciplines. Therefore, the discipline system of engineering management major should focus on the combination of practice and theory study during each learning stage, establishing sound professional skills training norms, strengthening the performance evaluation of education system, and then establishing a more complete discipline system.

The professional teacher's ability includes the theoretical competence and the practical teaching ability. In terms of theoretical quality, it is mainly to attract high-quality talents into the teaching team, hiring all kinds of outstanding professional talents at home and abroad to teach, and thereby improving the professional theoretical level of teachers. Practical teaching ability means that professional teachers should be invited out of the "pyramid", that is to say, teachers who are lacking enterprise practical experience should be sent to various engineering management companies for practical training by turns within a limited period, so as to change the current situation of "teacher pyramid" and encourage teachers to lead students to participate in project management through institutional guarantee.

\section{5. "Subject Integration" of Platform Development}

"Subject integration" based practical teaching platform can be further realised on the basis of three basic teaching systems development, the three-stage goal definition, and the strong support of the two elements. The realization path of "subject integration" of practical teaching platform of engineering management specialty can be summarized as "two ways and two directions".

The two ways include the teaching of scenario simulation and project case. 1) 
scenario simulation teaching requires professional teachers to combine theoretical knowledge with the virtual case, creating a specific project background with relevant knowledge through the characters and scenes design, such as the establishment of virtual simulation laboratory, simulation bidding laboratory, Building Information Modeling (BIM) experimental center and so on, which solves the singleness problem of the course for the purpose of interaction and agreement within different courses, and fully mobilizes students' learning enthusiasm, improves students' ability to knowledge application and problem-solving. 2) project-case-based teaching means that teachers bring the actual situation into classroom and practical teaching by selecting appropriate engineering projects. Given the background of students' understanding of the basic case conditions, "learn by doing" can be effectively realized according to different grades and the master of professional knowledge, preliminary feasibility study of varying degrees of involvement in project management, and practical work like project financing decision discussion, project bidding, project construction management, engineering cost management and BIM model construction, etc. which will further promote the organic combination of theory and practice.

The two directions refer to "integration of course teaching" and "integration of specialty and social ability". 1) Course teaching integration is mainly realized by relying on discipline system and professional teachers. Engineering management is a comprehensive subject. Traditional curriculum setting is isolated and lack of connection among courses, which easily lead to fragmentation of knowledge learnt by students. In the process of developing the curriculum system, on the one hand, knowledge in engineering technology, engineering economy, project management, information technology and other fields should be systematically sorted out to optimize the knowledge structure; On the other hand, we need to consult opinions from many aspects, including from industry experts and scholars, business managers, etc. With course teaching integration, there is no disconnection among courses and no conflicts in the practical process. 2) Integration of major and social ability is to effectively connect professional knowledge and social ability so as to better play the role of professional knowledge. That is to say, on the basis of certain social ability, students can use professional knowledge to well serve the society. The professional knowledge and ability training are divided through the framework teaching in order to clearly define the connection among the parts. Through the construction of "integrated" practical teaching platform, it gives full play to the pivotal role of talents training, realizes the integration of professional knowledge education and social ability training, and then promotes the construction of integrated teaching system of engineering management major.

\section{Conclusion}

The construction and application of engineering management teaching platform play an important role in improving the quality of practical teaching and cultivating high-quality engineering management professionals. By sorting the basic 
teaching systems of the platform, this paper analyzes the objectives of the three stages of the platform operation, discusses the key "two elements" supporting the platform construction, and puts forward the idea of "subject integration" for the platform development from "two directions and two ways".

\section{Acknowledgements}

This research is financially supported by the Teaching Reform Research Program of Jiangxi Normal University with the topic of "Research on self-learning platform construction and application of engineering management major based on MR technology" (JXSDJG1773), and the Research and Planning Fund for Humanities and Social Sciences of Jiangxi education department named "Research on the mechanism and policies of environmental regulations affecting green economic growth-a case study of the Yangtze River Economic Belt" (GL18125).

\section{Conflicts of Interest}

The authors declare no conflicts of interest regarding the publication of this paper.

\section{References}

[1] Dai, X.Y. (2011) Sand Table Simulation of Project Management in Professional Practice Teaching of Project Management. Experimental Technology and Management, 28, 162-164, 168.

[2] Fu, F. and Zhang, T. (2017) Practical Education Reform in Construction Management Discipline Based on "Virtual-Real" Building Information Hodelling. Research and Exploration in Laboratory, 36, 192-195.

[3] Milgram, P. and Kishino, F. (1994) A Taxonomy of Mixed Reality Visual Displays. IEICE Transactions on Information and Systems, 77, 1321-1329.

[4] Huang, J., Han, D.Q., Chen, Y.N., et al. (2016) A Survey on Human-Computer Interaction in Mixed Reality. Journal of Computer-Aided Design \& Computer Graphics, 28, 869-880.

[5] Azuma, R., Baillot, Y., Behringer, R., et al. (2001) Recent Advances in Augmented Reality. IEEE Computer Graphics and Applications, 21, 34-47. https://doi.org/10.1109/38.963459

[6] Mohr, P., Kerbl, B., Donoser, M., et al. (2015) Retargeting Technical Documentation to Augmented Reality. Proceedings of the 33rd Annual ACM Conference on Human Factors in Computing Systems, ACM Press, New York, 3337-3346.

[7] Chen, Q., Liu, P.H. and Chen, Z. (2016) A Comparative Research of Talent Cultivation Mode of Engineering Management between Chinese and Germany Universities. Science \& Technology Progress and Policy, 33, 143-146.

[8] Zhang, C.Y., Zhou, J.N. and Men, X.J. (2011) Project Management Sand-TableSimulation in the Design and Practice of a Comprehensive Course Project in Construction Management. Research and Exploration in Laboratory, 30, 142-146.

[9] Li, H.D. and Miao, J.Y. (2012) Analysis of Construction of Simulation Lab for Engineering Management Specialty. Research and Exploration in Laboratory, 31, 170-172. 